\title{
A Single Amino Acid Substitution in the Intervening Region of 129K Protein of Cucumber Green Mottle Mosaic Virus Resulted in Attenuated Symptoms
}

\author{
H. Chen, ${ }^{1,2, \dagger}$ M. Ino, ${ }^{3}$ M. Shimono, ${ }^{3}$ S. G. Wagh, ${ }^{1}$ K. Kobayashi, ${ }^{1}$ T. Yaeno, ${ }^{1}$ N. Yamaoka, ${ }^{1}$ G. Bai, ${ }^{2,4}$ and M. Nishiguchi ${ }^{1, \dagger}$ \\ ${ }^{1}$ Faculty of Agriculture, Ehime University, Matsuyama, Ehime 790-8566, Japan \\ 2 Department of Agronomy, Kansas State University, Manhattan, KS 66506, U.S.A. \\ ${ }^{3}$ National Institute of Agrobiological Sciences, Tsukuba, Ibaraki 305-8602, Japan \\ ${ }^{4}$ Hard Winter Wheat Genetics Research Unit, U.S. Department of Agriculture-Agriculture Research Service, Manhattan, KS 66506, \\ U.S.A. \\ Accepted for publication 25 September 2019.
}

\begin{abstract}
Cucumber green mottle mosaic virus (CGMMV), a member of the genus Tobamovirus, is a major threat to economically important cucurbit crops worldwide. An attenuated strain (SH33b) derived from a severe strain (SH) of CGMMV caused a reduction in the viral RNA accumulation and the attenuation of symptoms, and it has been successfully used to protect muskmelon plants against severe strains in Japan. In this study, we compared GFP-induced silencing suppression by the $129 \mathrm{~K}$ protein and the methyltransferase domain plus intervening region (MTIR) of the $129 \mathrm{~K}$ protein between the $\mathrm{SH}$ and $\mathrm{SH} 33 \mathrm{~b}$ strains, respectively. As a result, silencing suppression activity (SSA) in the GFP-silenced plants was inhibited efficiently by the MTIR and $129 \mathrm{~K}$ protein of SH strain, and it coincided with drastically reduced accumulation of GFP-specific small
\end{abstract}

ABSTRACT interfering RNAs (siRNAs) but not by that of SH33b strain. Furthermore, analyses of siRNA binding capability (SBC) by the MTIR of $129 \mathrm{~K}$ protein and $129 \mathrm{~K}$ protein using electrophoretic mobility shift assay revealed that SBC was found with the MTIR and $129 \mathrm{~K}$ protein of SH but not with that of SH33b, suggesting that a single amino acid mutation (E to G) in the MTIR is responsible for impaired SSA and SBC of SH33b. These data suggest that a single amino acid substitution in the intervening region of $129 \mathrm{~K}$ protein of CGMMV resulted in attenuated symptoms by affecting RNA silencing suppression.

Keywords: attenuated virus, biological control, cucumber green mottle mosaic virus, RNA silencing suppression, tobamovirus
Cucumber green mottle mosaic virus (CGMMV) is a member of the genus Tobamovirus in the family Virgaviridae with a positivesense, single-stranded RNA of $6.4 \mathrm{~kb}$ and encodes $186 \mathrm{kDa}(\mathrm{K})$, $129 \mathrm{~K}, 29 \mathrm{~K}$, and $17.3 \mathrm{~K}$ proteins (Ugaki et al. 1991); $186 \mathrm{~K}$ is the read-through product of $129 \mathrm{~K}$, and both are RNA replication proteins. The $29 \mathrm{~K}$ and $17.3 \mathrm{~K}$ proteins are movement and coat proteins (CPs), respectively. CGMMV is prevalent particularly in cucurbitaceous crops, such as watermelon, muskmelon, and cucumber (Ainsworth 1935; Dombrovsky et al. 2017; Fletcher et al. 1969; Inoue et al. 1967; Rajamony et al. 1987). An attenuated strain (SH33b) of CGMMV was isolated through nitrous acid, ultraviolet (UV) irradiation, and high-temperature treatment, and it has been used for cross-protection of muskmelon in greenhouses in Japan (Motoyoshi and Nishiguchi 1988; Nishiguchi and Kobayashi 2011; Oosawa 1990).

Plants have developed a sophisticated system termed RNA silencing against the invading viruses (Baulcombe 1999; Bosher and Labouesse 2000; Burgyán 2008: Catalanotto et al. 2000; Matzke et al. 2001; Waterhouse et al. 2001). However, many viruses have evolved counterdefensive strategies to counteract RNA silencing by encoding a viral suppressor of RNA silencing (VSR), a protein that inhibits RNA silencing (Burgyán 2008;

†Corresponding authors: H. Chen; huichen98@ksu.edu, and M. Nishiguchi; mnishigu@agr.ehime-u.ac.jp

Funding: This work was supported by Program for Promotion of Basic and Applied Researches in Bio-oriented Industry grant Technology Research Promotion Program for Agriculture, Forestry, Fisheries and Food Industry and Ministry of Education, Culture, Sports, Science and Technology of Japan Grant-in-Aid for Scientific Research (C) 24580065 (to M. Nishiguchi).

The author(s) declare no conflict of interest.

(c) 2020 The American Phytopathological Society
Csorba et al. 2015). A number of VSRs have been reported, including HC-Pro protein of tobacco etch virus (Anandalakshmi et al. 1998; Kasschau and Carrington 1998), P19 protein of tomato bushy stunt virus (Silhavy et al. 2002), 2b protein of cucumber mosaic virus (CMV) (Guo and Ding 2002), p38 protein of turnip crinkle virus (Thomas et al. 2003), and p21 protein of beet yellows virus (Reed et al. 2003). Tobamovirus replication proteins are reported to be responsible for RNA silencing suppression (Csorba et al. 2007; Ding et al. 2004; Kubota et al. 2003; Várallyay and Havelda 2013; Vogler et al. 2007; Wang et al. 2012). These proteins suppress RNA silencing by preventing small interfering RNA (siRNA) generation, inhibiting the incorporation of siRNAs into effector complexes, or interfering with one of the effector complexes in different RNA silencing pathways (Burgyán 2008).

Previously, we reported that RNA silencing was suppressed by a CGMMV severe strain SH but partially by strain SH33b, and we found that the $129 \mathrm{~K} / 186 \mathrm{~K}$ protein region of the genome was responsible for RNA silencing suppression activity (SSA) (Ali et al. 2016). Mutant plasmid construct from an attenuated strain of tomato mosaic virus (ToMV) showed much lower extent of RNA silencing suppression compared with severe strain (Kubota et al. 2003). Furthermore, two types of amino acid substitutions at amino acid position 284 (R284A or R284S) in the methyltransferase domain (MT) of CGMMV isolate responsible for stable attenuated symptoms have been implicated as potential candidates for crossprotection (Liu et al. 2017). However, it is not known whether these two mutants affect RNA SSA. In this study, as a step toward better understanding the underlying mechanism of symptom attenuation in the SH33b strain in relation to silencing suppression, we further investigated the SSA of the $129 \mathrm{~K}$ protein as well as methyltransferase domain plus intervening regions (MTIR) from SH33b and $\mathrm{SH}$ strains of CGMMV. The small interfering RNA binding capability (SBC) of the MTIR and $129 \mathrm{~K}$ proteins in the two strains was also analyzed using electrophoretic mobility shift assay (EMSA), and 
the three-dimensional (3D) structures of the MTIR of $129 \mathrm{~K}$ proteins from the two strains were predicted.

\section{MATERIALS AND METHODS}

Plants and viruses. Muskmelon (Cucumis melo 'Earls Favorite') and $G F P$-overexpressed (no. 11), and GFP-silenced (no. 24) Nicotiana benthamiana (Shimono et al. 2005) were used for virus inoculation and/or agroinfiltration. Onion (Allium cepa) and rice (Oryza sativa) were used for particle bombardment. The complementary DNA (cDNA) clones of pCG3A (severe strain) and pCG22 (attenuated strain) were described previously (Tan et al. 1997; Ugaki et al. 1991).

Plasmid constructs. DNA fragments of the MTIR (1,899 base pairs) and $129 \mathrm{~K}$ protein $(3,435$ base pairs) from cDNA plasmids of pCG3A and pCG22 were amplified by PCR using forward primer 5'-CGGGATCCATGGCAAACATTAATGAACAAATC-3' containing the BamHI site (underlined) and reverse primer $5^{\prime}$ CGGAGCTCCTACATCAACACTATATCCTCCATATC-3' (MT)

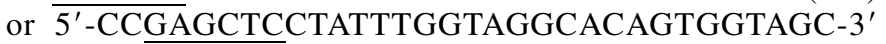
$(129 \mathrm{~K})$ containing the $S a c \mathrm{I}$ site (underlined), respectively. The fragments were digested with $\mathrm{BamHI}$ and $\mathrm{SacI}$ restriction enzymes and ligated into similarly digested pBI121 vector. The resulting plasmids (pCGSH-MTIR, pCGSH-129K, pCG33b-MTIR, and pCG33b-129K) were used for particle bombardment. The plasmid of p35S-dsGFP (Miki and Shimamoto 2004) was digested with BamHI and SacII restriction enzymes to remove dsGFP fragment and blunt-end religated; the resulting plasmid of empty vector (EV) was used for particle bombardment as a control. For the Agrobacterium-mediated transient gene expression, the fragments of the MTIR and $129 \mathrm{~K}$ protein from both strains were amplified by PCR using a forward primer 5'-CGGGATCCATGGCAAACATTAAT GAACAAATC-3' (BamHI; underlined) and a reverse primer 5' CGGAATTCCTACATCAACACTATATCCTCCATATC-3' (MTIR) or 5'-CCGAATTCCTATTTGGTAGGCACAGTGGTAGC-3' (129K; EcoRI; underlined), and the fragments were digested with BamHI and $E c o$ RI restriction enzymes and inserted into similarly digested pBICP35 (Takeda et al. 2005), which was digested by the same enzymes. The resulting plasmids were named pSH-MTIR, pSH$129 \mathrm{~K}$, pSH33b-MTIR, and pSH33b-129K. For siRNA binding analysis, the fragments of the MTIR and $129 \mathrm{~K}$ protein from SH and SH33b strains were amplified by PCR using gateway attB forward primer 5'-GGGGACAAGTTTGTACAAAAAAGCAGGCTTC + MTIR or $129 \mathrm{~K}-3^{\prime}$ (without start codon) and reverse primer $5^{\prime}$ GGGGACCACTTTGTACAAGAAAGCTGGGTC + MTIR or $129 \mathrm{~K}-3^{\prime}$ and recombined into the entry vector pDONR221 using Gateway BP Clonase II Enzyme mix (Invitrogen). The target fragments in pDONR221 vector were further recombined into the Gateway-compatible pEarleyGate-201 using Gateway LR Clonase Enzyme mix (Invitrogen), resulting in pCGSHt-MTIR, pCGSHt$129 \mathrm{~K}$, pCG33bt-MTIR, and pCG33bt-129K that expressed the hemagglutinin (HA)-tagged MTIR and $129 \mathrm{~K}$ proteins. All plasmids were verified by DNA sequencing.

Transient suppression assay by particle bombardment. Particle bombardment was performed as described previously (Chen et al. 2008, 2010). Fluorescence images of GFP- and DsRedexpressing cells in all treatments were captured by a C7070 digital camera (Olympus; https://olympus-imaging.jp) using the same illumination intensity and exposure time under an IX70 fluorescence microscope (Olympus; https://www.olympus-lifescience. com/en/microscope-resource/).

Transient suppression assay by agroinfiltration. The Agrobacterium-mediated transient suppression assay using Agrobacterium tumefaciens strain $\mathrm{C} 58 \mathrm{C} 1$ was performed as described previously (Kubota et al. 2003). The concentration of the Agrobacterium carrying respective plasmid constructs in all infiltration experiments was normalized to 1.0 optical density (OD) at $600 \mathrm{~nm}$. Infiltrated plants were grown at $22^{\circ} \mathrm{C}$, and GFP fluorescence was observed at 3 days postinoculation (dpi) with a 100-W handheld UV lamp (UV Products). Photographs were taken using a digital camera (Fujifilm; FinePix S1 Pro).

RNA isolation and analysis. Total RNA extraction and northern blot analysis for GFP messenger RNA (mRNA) and GFPspecific siRNAs were performed as described previously (Chen et al. 2008; Shimono et al. 2005). The band intensity of GFP mRNA and $G F P$-specific siRNAs in the captured images was measured using ImageJ software (https://imagej.nih.gov/ij/index.html). Total RNA was used for reverse transcription PCR (RT-PCR) and reverse transcription quantitative PCR (RT-qPCR) for GFP mRNA and CGMMV RNA. Synthesis of cDNA was performed using $1 \mu \mathrm{g}$ of total RNA and M-MLV Reverse transcription (Nippon Gene) with a reverse primer SH-CP-3' (5'-AGCGTTAAGCGACTCAGC-3'), and the $\mathrm{CP}$ fragment was amplified with the $C P$-specific primers, forward primer SH-CP-5' (5'-CCGGATATCATGGCTTACAATCC GATCA-3') and SH-CP-3'. The PCR amplifications were performed at $94^{\circ} \mathrm{C}$ for 2 min followed by 30 cycles of amplification $\left(94^{\circ} \mathrm{C}\right.$ for $30 \mathrm{~s}, 56^{\circ} \mathrm{C}$ for $20 \mathrm{~s}$, and $72^{\circ} \mathrm{C}$ for $40 \mathrm{~s}$ ). GFP was amplified as reported previously (Chen et al. 2008). Actin and $L 23$ genes were used as internal standard for RT-PCR and RT-qPCR, respectively (Liu et al. 2012).

siRNA binding analysis. Crude HA-tagged protein was extracted from $N$. benthamiana leaves at 2 days after agroinfiltration with respective plasmids expressing MTIR or $129 \mathrm{~K}$ protein of SH (pCGSHt-MTIR and pCGSHt-129K) and SH33b (pCGSH33bt-MTIR and pCGSH33bt-129K) using a protocol described previously by Kurihara et al. (2007); 21-nucleotide double-stranded small interfering RNAs (ds-siRNAs) were in vitro transcribed and digoxigenin (DIG) labeled as described (Chen et al. 2015, 2016). Western blot and EMSAs were performed using previously described protocols (Kurihara et al. 2007; Valli et al. 2008, 2011).

3D structure modeling analysis. The $3 \mathrm{D}$ structures of the MTIR from the SH and SH33b strains were modeled using the I-TASSER web server (Zhang 2008) based on multiple threading alignments by LOMETS and iterative TASSER simulations (Roy et al. 2010). The protein secondary structure and the protein with high structure similarity in the Protein Data Bank (https:// www.rcsb.org/) were obtained using PyMol (https://pymol.org/2/).

\section{RESULTS}

CGMMV SH infection suppressed RNA silencing. To investigate whether RNA silencing was suppressed by CGMMV infection, crude sap from CGMMV SH-infected leaves was used to inoculate GFP-silenced N. benthamiana plants (no. 24) (Shimono et al. 2005). At 16 dpi, severe mosaic symptoms were observed in coincidence with high GFP expression and viral accumulation on systemically infected leaves, whereas the GFP expression and disease symptoms did not appear in the mock-inoculated leaves (Fig. 1). Accumulation of GFP mRNA and $C P$ in the highfluorescence area in the infected leaves was higher than that in the low-fluorescence area (Fig. 1). Northern blot, RT-PCR, and RTqPCR analyses showed a higher level of GFP mRNA and viral accumulation in systemically infected leaves than the mockinoculated leaves of plant no. 24. These results demonstrate that CGMMV infection suppressed GFP silencing in plant no. 24, and they lead to the next step to examine differential suppression activities between the two strains, SH and SH33b.

Differential RNA SSAs between the SH and SH33b strains of CGMMV using particle bombardment. To compare the RNA SSAs between the two CGMMV strains, a transient suppression assay was conducted by particle bombardment of the plasmids of severe and attenuated strains that carry either the fragments of the MTIR (1,899 base pairs) or $129 \mathrm{~K}$ protein $(3,435$ base pairs) (Fig. 2A). p35S-GFP and p35S-dsGFP were used as reporter and inducer of RNA silencing, respectively, and Discosoma red fluorescent 
protein gene (DsRed; pUbq-DsRed) was used as an internal control (Miki and Shimamoto 2004). The cobombardment mixtures with different combinations of plasmids $(5 \mu \mathrm{g}$ of each plasmid and $10 \mu \mathrm{g}$ of each silencing inducer) include (i) pUbq-DsRed (expressing DsRed), p35S-GFP (expressing GFP), EV, and pBI221 (control vector); (ii) pUbq-DsRed, p35S-GFP, p35S-dsGFP (silencing inducer), and pBI221; (iii) pUbq-DsRed, p35S-GFP, p35S-dsGFP, and pCGSH-MTIR; (iv) pUbq-DsRed, p35S-GFP, p35S-dsGFP, and pCG33b-MTIR; (v) pUbq-DsRed, p35S-GFP, p35SdsGFP, and pCGSH-129K; and (vi) pUbq-DsRed, p35S-GFP, p35S-dsGFP, and pCG33b-129K. When mixture (i) was cobombarded into the epidermal cells of onion, both GFP and DsRed fluorescent expressions reached near the maximum levels at $36 \mathrm{~h}$ postbombardment (Fig. 2B and C). For consistency, samples were taken at $36 \mathrm{~h}$ postbombardment for analysis in subsequent experiments. Similarly, fluorescent images were obtained from the same GFP-expressing and DsRed-expressing cells using their respective fluorescence filters. The number of cells with GFP or DsRed fluoresce was counted from six independent experiments $(n=6)$ for quantitative analysis. When mixture (ii) that contains a silencing inducer (p35S-dsGFP) to trigger specific silencing against GFP expression was cobombarded, the number of GFP fluoresced cells was drastically reduced (Fig. 2B and C). When mixtures (iii) and (v), which carry a silencing suppressor from the SH strain, were cobombarded, the number of GFP fluoresced cells increased. However, when mixtures (iv) and (vi), which include a silencing suppressor from the SH33b strain, were cobombarded, the number of GFP fluoresced cells did not increase. In contrast, the number of cells with DsRed fluorescence remained high in all of the treatments. These results suggest that CGMMV strain $\mathrm{SH}$ but not $\mathrm{SH} 33 \mathrm{~b}$ suppressed GFP silencing, likely by encoding the strong silencing suppressor proteins $129 \mathrm{~K} /$ MTIR. The similar results were obtained using rice shoot tissues (data not shown).

Comparison of RNA SSAs and SBCs between the strains of SH and $\mathrm{SH} 33 \mathrm{~b}$ by the Agrobacterium-mediated transient expression. To further investigate RNA SSAs of CGMMV strains, the Agrobacterium-mediated transient suppression assay
A
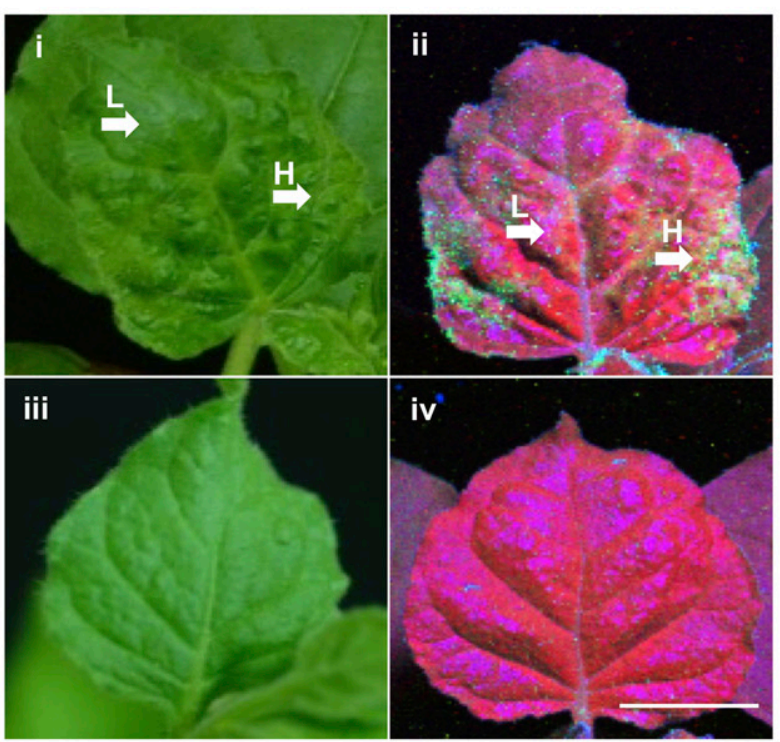

B

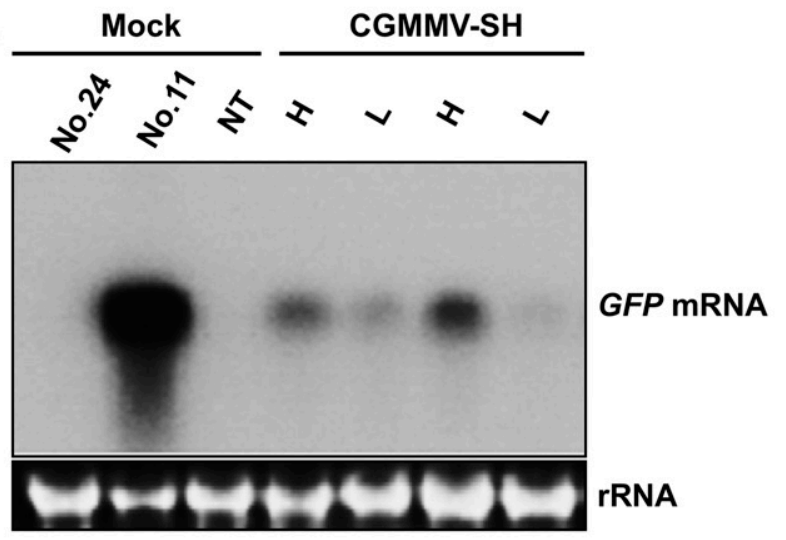

C

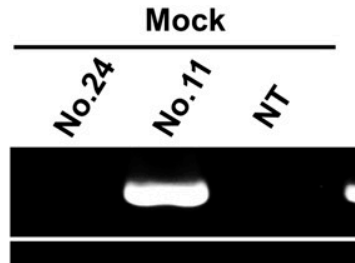

CGMMV-SH
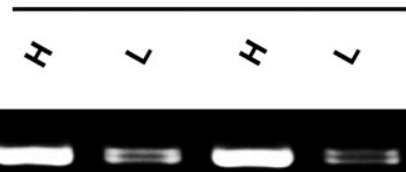

GFP
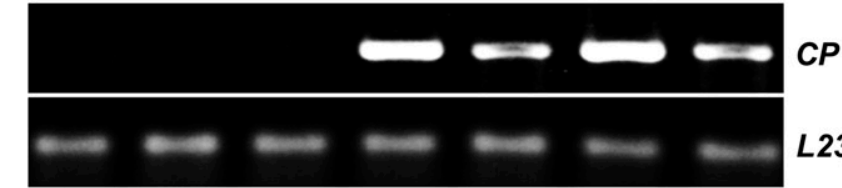

D

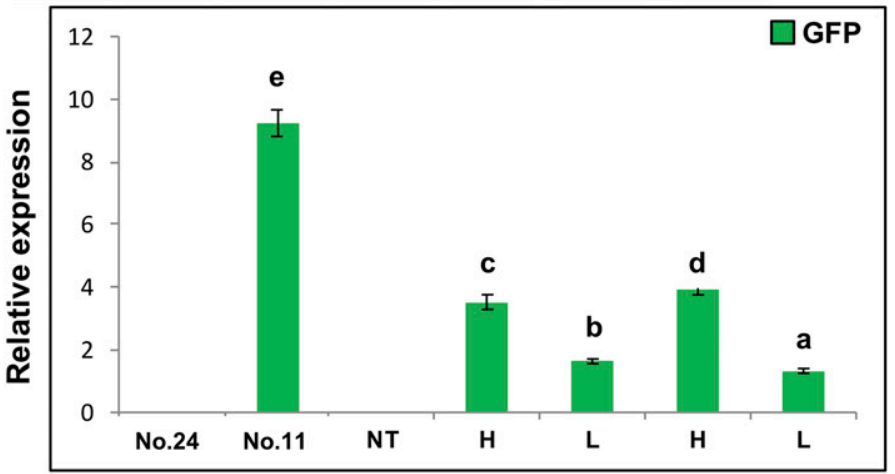

E

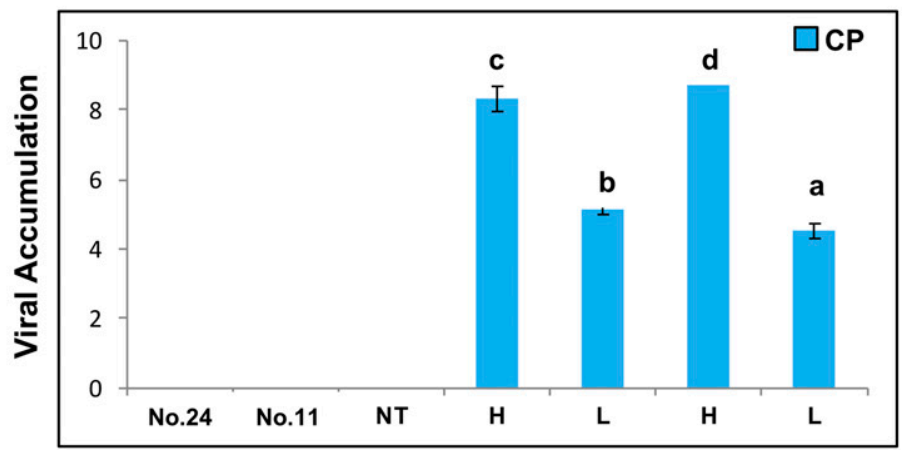

Fig. 1. Symptoms associated with suppression of RNA silencing in a transgenic GFP-silenced Nicotiana benthamiana line (no. 24) infected by cucumber green mottle mosaic virus (CGMMV) SH strain. A, Viral symptoms and GFP fluorescence in the upper leaves were monitored in i and ii, a CGMMV SH-infected plant and iii and iv, a mock-inoculated plant at 16 days postinoculation. Images were taken under $\mathbf{i}$ and iii, white light and ii and iv, ultraviolet light. i and ii, Arrows indicate low (L) and high (H) intensity of fluorescence of GFP. The white scale bar represents $2 \mathrm{~cm}$. B, Level of GFP messenger RNA accumulation detected by northern blot analysis. $\mathrm{H}$ and L indicate high and low intensity of GFP fluorescence in CGMMV SH-infected leaves, respectively. Mock, inoculation with buffer; no. 11, GFP-overexpressed plant; no. 24, GFP-silenced plant; NT, nontransformed plant; rRNA, ribosomal RNA. C, GFP expression and viral accumulation (coat protein $[\mathrm{CP}]$ ) were detected by reverse transcription PCR analysis. The $L 23$ gene was used as an internal control. D, GFP expression and E, viral accumulation were also detected by reverse transcription quantitative PCR analysis. The actin gene was used as an internal control. Data are mean \pm standard error $(n=3)$. Values with different letters differ significantly among inoculated leaves in Tukey's test at $P<0.05$. 
was performed. As described above, two fragments with only one-amino acid difference in the MTIR (1,899 base pairs) and $129 \mathrm{~K}$ protein $(3,435$ base pairs) derived from the two CGMMV strains were cloned into a pBICP35 expression vector, resulting in the plasmids pSH-MTIR, pSH-129K, pSH33b-MTIR, and pSH33b-129K. GFP fluorescence in infiltrated leaves from GFPsilenced $N$. benthamiana plants (no. 24) was observed under a UV light at $3 \mathrm{dpi}$ (Fig. 3A). GFP fluorescence was much stronger in the area expressing the $129 \mathrm{~K}$ protein from strain $\mathrm{SH}(\mathrm{pSH}-129 \mathrm{~K})$ than in the area expressing the same protein from strain $\mathrm{SH} 33 \mathrm{~b}$ (pSH33b-129K) (Fig. 3A). GFP silencing was suppressed by expressing MTIR from pSH-MTIR (SH) but not by pSH33bMTIR (SH33b) in GFP-silenced N. benthamiana plants (no. 24) (Fig. 3A). Northern blot analysis showed that the level of GFP mRNA in leaves expressing the MTIR or $129 \mathrm{~K}$ protein from strain $\mathrm{SH}$ was higher than that in leaves expressing the MTIR or $129 \mathrm{~K}$ protein from strain $\mathrm{SH} 33 \mathrm{~b}$ (Fig. 3B). The level of GFP siRNAs in leaves expressing the MTIR or $129 \mathrm{~K}$ protein from strain SH was much lower than that for the MTIR or $129 \mathrm{~K}$ protein from strain SH33b (Fig. 3C). These results indicate that the MTIR or 129K protein from CGMMV SH was a stronger suppressor of RNA silencing compared with CGMMV strain SH33b. These data also suggest that the MTIR and $129 \mathrm{~K}$ proteins of CGMMV strain SH independently suppressed GFP-induced RNA silencing in $N$. benthamiana plants.

MTIR and 129K proteins of SH and SH33b differentially bound to siRNA in EMSA. To further examine whether $129 \mathrm{~K}$ of CGMMV can bind siRNA and if this capacity is correlated with its SSA, we performed EMSA using HA-tagged MTIR or $129 \mathrm{~K}$ protein from $N$. benthamiana leaves agroinfiltrated with the plasmids expressing the MTIR and $129 \mathrm{~K}$ protein of SH (pCGSHtMTIR and pCGSHt-129K) or SH33b (pCGSH33bt-MTIR and pCGSH33bt-129K), respectively. The MTIR and 129K proteins of SH caused a shift of DIG-labeled 21-nucletide ds-siRNA and produced a protein:siRNA complex (Fig. 3D, upper left and lower left panels). In contrast, the MTIR and $129 \mathrm{~K}$ protein of SH33b did not affect the 21-nucleotide ds-siRNA mobility and were unable to generate a protein:siRNA complex at detectable levels (Fig. 3D, upper right and lower right panels). These results indicated that a single amino acid substitution from $\mathrm{E}$ to $\mathrm{G}$ at 480 amino acid position in the intervening region (IR) of $\mathrm{SH} 33 \mathrm{~b}$ impaired SBC.

Structural difference in the MTIR of $129 \mathrm{~K}$ protein between SH and SH33b strains. As previously discussed, a single nucleotide change (A to G) in the MTIR of $129 \mathrm{~K}$ protein of SH33b causes an amino acid substitution $E$ to $G$ at amino acid position 480 (Tan et al. 1997). To further investigate whether impairing SSA and SBC in the SH33b is owing to any structural changes in the MTIR of $129 \mathrm{~K}$ protein, the 3D structures of the MTIR 129K protein from both SH and SH33b strains were predicted using web server I-TASSER (Zhang 2008). An appropriate template was identified by LOMETS by searching for homologous proteins in a representative Protein Data Bank structure library (Roy et al. 2010). The protein's secondary structures as well as proteins with high structural similarity in the Protein Data Bank were then obtained. Template 3 ungC (Cmr2) (Cocozaki et al. 2012), the largest and essential subunit of a CRISPR (clusters of regularly interspaced short palindromic repeats) RNA-Cas (CRISPR-associated) RNA silencing complex, was generated and ranked as the best template (Wu and Zhang 2007). The MTIR of $129 \mathrm{~K}$ protein in SH had a high coverage $(81.5 \%)$ of template 3 ungC. The 3D structure of the MTIR of $129 \mathrm{~K}$ protein was triangular, containing many $\alpha$-helices and loops as well as several $\beta$-sheets (Fig. 4A and B). The SH's MTIR domain had amino acid $E$ at position 480 in the $\alpha$-helix (Fig. 4C). However, the MTIR from SH33b had G at this position, which was between a coil structure and an $\alpha$-helix structure (Fig. 4D). The amino acid substitution resulted in a shorter $\alpha$-helix but longer random coil. Comparing the exposed surface area of the MTIR of $129 \mathrm{~K}$ protein between SH and SH33b showed that $\mathrm{E}$ at amino acid position 480 in $\mathrm{SH}$ was completely exposed (Fig. 4E), but a glycine residue at amino acid position 480 was hidden entirely in SH33b (Fig. 4F). The structural divergence of the MTIR of $129 \mathrm{~K}$ protein between SH and SH33b is consistent with their functional roles in SSA. Therefore, a single amino acid substitution at amino acid position 480 in the IR in SH33b resulted in a structural change in the suppressor, which is most likely responsible for impairing SBC and SSA.

\section{DISCUSSION}

In this study, we investigated SSA of CGMMV $129 \mathrm{~K}$ protein by using a $G F P$-silenced transgenic $N$. benthamiana line, particle bombardment, and transient agroinfiltration assays. The CGMMV $\mathrm{SH}$ strain infection resulted in suppression of GFP silencing in the no. 24 line accompanied by severe mosaic symptoms in the systemically infected leaves. The levels of suppression activity positively correlated with the intensity of symptoms (Fig. 1). The effects of suppressor activity between the $\mathrm{SH}$ and $\mathrm{SH} 33 \mathrm{~b}$ strains were compared in a transient suppression assay by particle bombardment and agroinfiltration (Figs. 2B and 3A). Both results demonstrated that $129 \mathrm{~K}$ protein encoded by CGMMV $\mathrm{SH}$ is a strong suppressor of RNA silencing, even if the MTIR of $129 \mathrm{~K}$ protein can also suppress local silencing in the absence of other CGMMV-encoded proteins (Figs. 2B and 3A). This

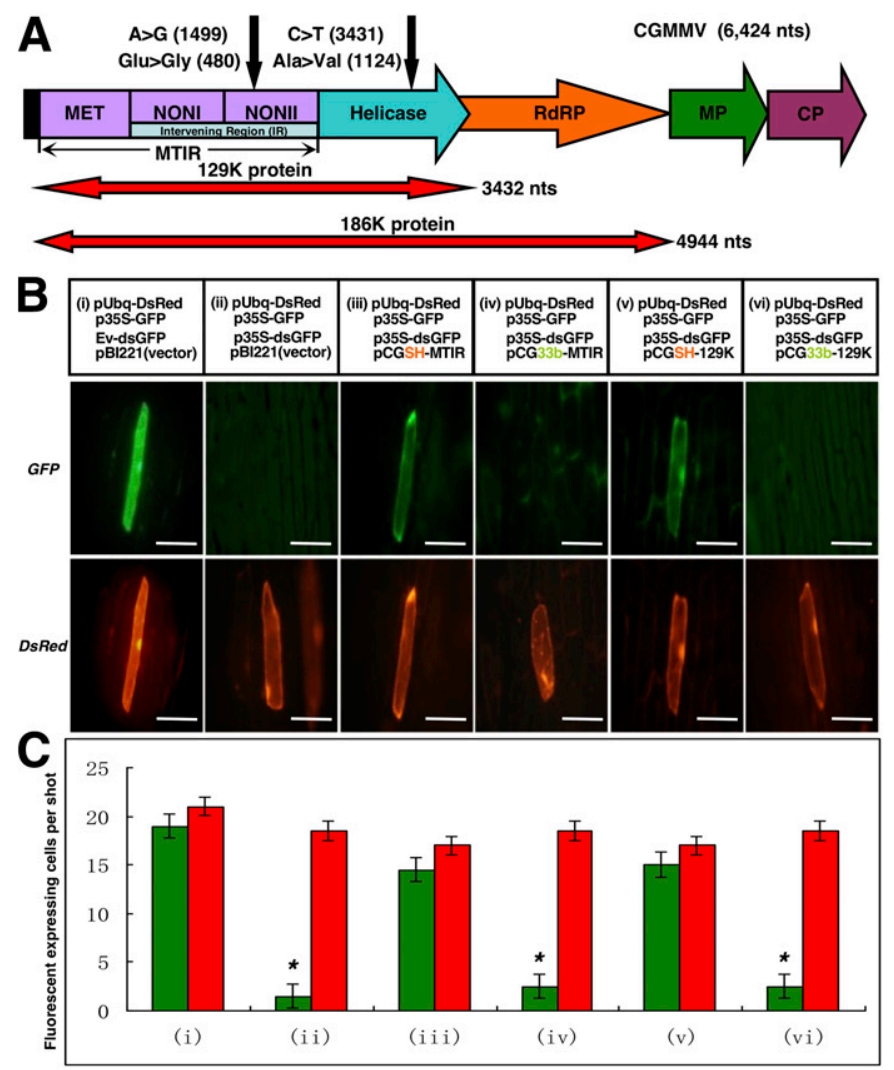

Fig. 2. A, Comparison of genome organization between cucumber green mottle mosaic virus (CGMMV) SH severe and SH33b attenuate strains. CP, coat protein. B, GFP silencing suppressed by expressing the methyltransferase domain plus intervening region (MTIR) and $129 \mathrm{~K}$ protein encoded by CGMMV SH in the epidermal cells of onion bulb through particle bombardment. Fluorescent images of GFP and DsRed (control) expression in the different mixtures of plasmids at $36 \mathrm{~h}$ postcobombardment. Scale bar $=25 \mu \mathrm{m}$. C, Quantitative analysis of fluorescence-expressing cells per shot in the different mixtures of plasmids cobombarded. Data are mean \pm standard error $(n=6)$. $* P<0.05$ (Fisher's test) versus value of GFP-expressing cells in $\mathbf{i}$. 
MTIR result shows an important role of a single amino acid substitution at amino acid position 480 in the IR of SH33b (Tan et al. 1997) (Fig. 2A) for SSA. The MTIR of $126 \mathrm{~K}$ protein by tobacco mosaic virus (TMV) is involved in both cell-to-cell movement and long-distance movement in $N$. benthamiana (Knapp et al. 2005, 2007). Mutation in the IR of $126 \mathrm{~K}$ protein is one of the major pathogenicity determinants of Pepper mild mottle virus (PMMoV), which is responsible for the attenuated symptoms and decreased accumulation of the $\mathrm{CP}$ in infected pepper plants (Hagiwara et al. 2002; Ichiki et al. 2005; Yoon et al. 2006). It was reported that a single amino acid substitution in the MTIR of Paprika mild mottle virus replicase proteins led to a change in disease symptoms in inoculated Capsicum plants carrying the $H \mathrm{H}$ resistance gene at $24^{\circ} \mathrm{C}$ (Matsumoto et al. 2009). The IR of ToMV $130 \mathrm{~K}$ protein is also responsible for symptom attenuation and SSA (Kubota et al. 2003). RNA silencing suppression by ToMV 130K protein was thought to occur via $130 \mathrm{~K}$ protein in soluble fraction (Hagiwara-Komoda et al. 2008). They showed larger quantity of ToMV $130 \mathrm{~K}$ protein in soluble fraction than that of TLJ (a ToMV mutant and named TLJ), an attenuated strain, indicating that quantitative difference of $130 \mathrm{~K}$ protein caused different levels of silencing suppression.

Specific amino acids in the nonconserved region II (NONII) in the C-terminal half of the IR in TMV $126 \mathrm{~K}$ have been reported to be crucial for silencing suppression (Wang et al. 2012), which coincides with our result that one amino acid substitution occurred at amino acid position 480 located in NONII. In PMMoV, the mutations for attenuation were also located in NONII (Ichiki et al. 2005). The attenuated strain, CGMMV-VIROG-43, had the amino acid substitution at 534 and 698 amino acid positions in NONII, although another amino acid substitution occurred at 86 amino acid position in MT domain (Slavokhotova et al. 2016). Liu et al. (2017) showed that amino acid substitution at 284 (in NONI) amino acid positions in hn-CGMMV isolate (a CGMMV isolate obtained from Henan province, China) were involved in symptom attenuation. In the case of ToMV, the amino acid substitution in NONI affected silencing suppression (Kubota et al. 2003). The same amino acid substitution by in vitro mutagenesis in PMMoV was also found to

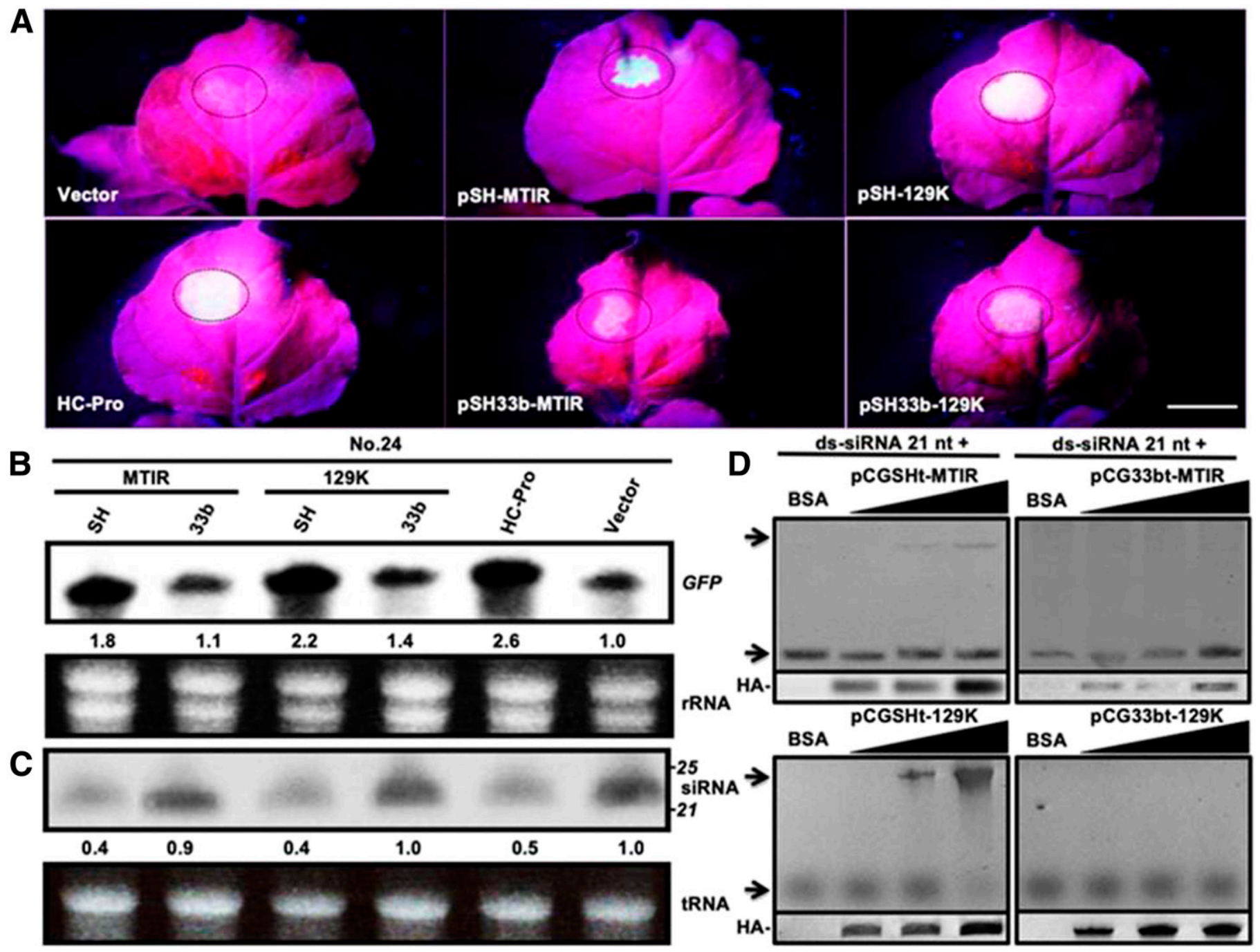

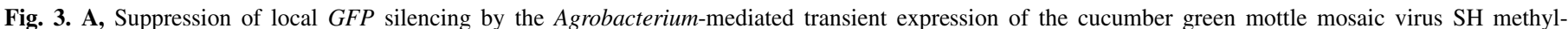

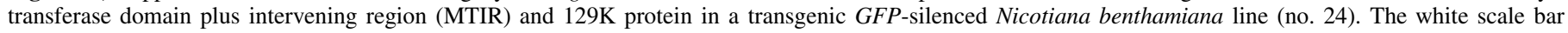

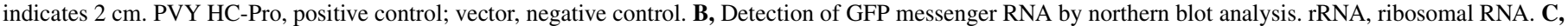

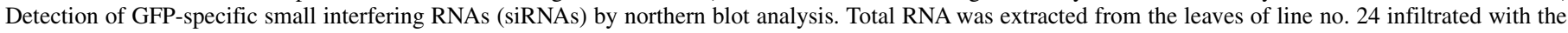

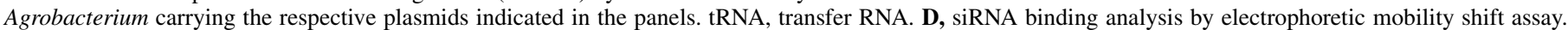

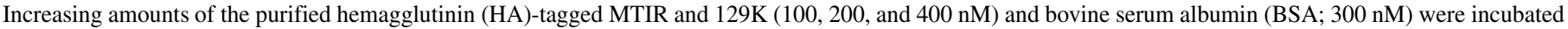

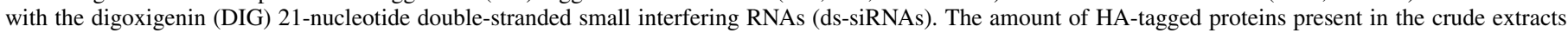

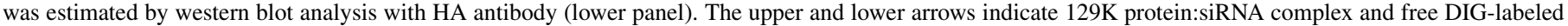
21-nucleotide ds-siRNAs, respectively. 
be involved in virus attenuation (Tsuda et al. 2007). Thus, NONI and/or NONII are responsible for symptom attenuation. Analysis of MTIR and $129 \mathrm{~K}$ protein SBC by EMSA revealed that SH showed SBC, whereas SH33b did not (Fig. 3D), suggesting that the single amino acid substitution in the IR of SH33b strain was sufficient for impairing SBC and SSA and eventually, led to the attenuated symptoms. This finding is also consistent with previous work that the cr-TMV (now belonging to the virus species turnip vein-clearing virus) $122 \mathrm{~K}$ and TMV-cg (now belonging to the virus species youcai mosaic virus) $126 \mathrm{~K}$ proteins acted as a silencing suppressor and had binding activity to small RNA duplexes (Csorba et al. 2007; Kurihara et al. 2007).

Here, we showed that SBC of CGMMV 129K protein of an attenuated strain was impaired, leading to its attenuation. SBC of viral silencing suppressors has been reported in many viruses so far (Burgyán 2008; Csorba et al. 2015). This is the first report of impaired SBC of silencing suppressor protein in a tobamovirus. So far, lower or impaired SBC has been reported for different attenuated strains/isolates in a tobamovirus (this study), a cucumovirus, CMV, (Goto et al. 2007), and a potyvirus, tobacco etch virus, (Torres-Barceló et al. 2010). Thus, it may be common among different viruses that lower/impaired SBC leads to attenuated symptom phenotypes. CP of CGMMV affects virus infectivity using several mutations, including single amino acid substitution (Zhang 2008). In SH33b, there is one amino acid substitution $\mathrm{A}$ to $\mathrm{V}$ at 156 amino acid position of $\mathrm{CP}$ (Tan et al. 1997). We cannot exclude the possibility that this substitution affects symptom attenuation. Generally, it is thought that infectivity/symptoms reflect a total sum of mutations all over the viral genome. Thus, it is reasonable to understand that not only RNA silencing but also, other mechanisms could affect symptoms in hosts as a total. Further investigation is needed for elucidation
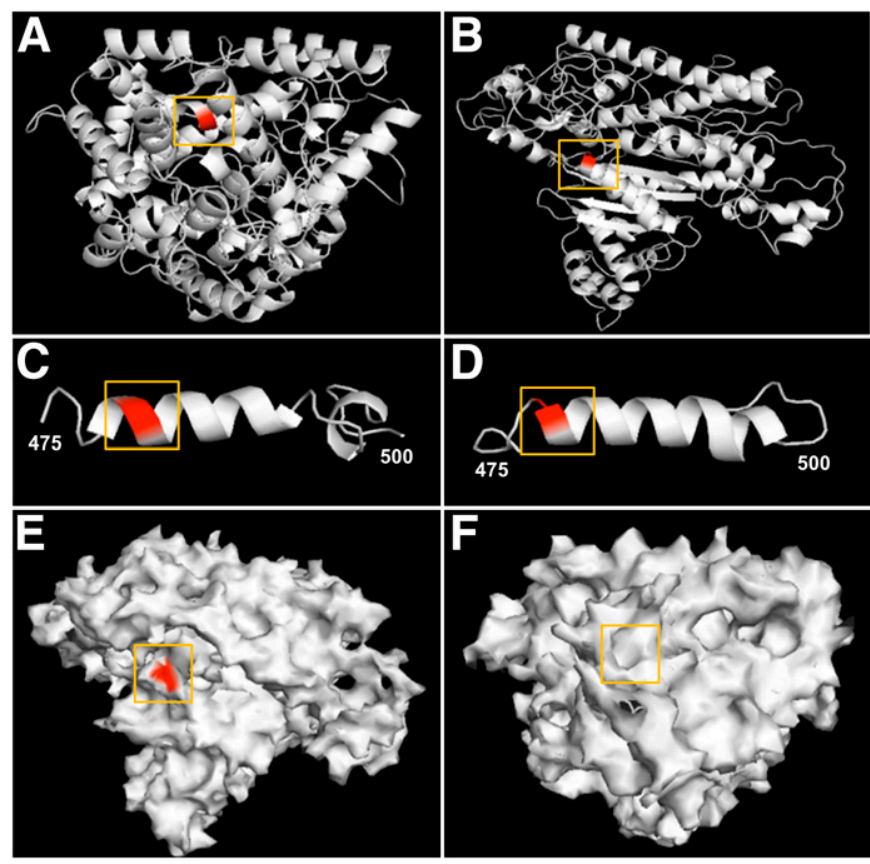

Fig. 4. Impairment of the suppression activity of RNA silencing probably resulting from a structural change of suppressor caused by a single amino acid substitution in the methyltransferase domain plus intervening region (MTIR) of $129 \mathrm{~K}$ protein of the SH33b strain. Modeling of the MTIR of $129 \mathrm{~K}$ protein in the cucumber green mottle mosaic virus $\mathrm{SH}$ and $\mathrm{SH} 33 \mathrm{~b}$ strains using the I-TASSER server with 3ungC $(\mathrm{Cmr} 2)$ as a template. The predicted cartoon structure is for A, SH-methyltransferase domain (MT) and B, SH33b-MT. Close views in the region from 475 to 500 are for $\mathbf{C}, \mathrm{SH}$ and $\mathbf{D}, \mathrm{SH} 33 \mathrm{~b}$. Exposed surface structures are for E, SH and F, SH33b. For clarity, the position of amino acid substitution at 480 amino acid is shown in red outlined with a yellow rectangle. of any effects of each mutation in SH33b. In conclusion, here we show that a single amino acid substitution from $\mathrm{E}$ to $\mathrm{G}$ at amino acid position 480 in the IR of CGMMV caused SSA and SBC to be repressed, contributing to symptom attenuation.

\section{ACKNOWLEDGMENTS}

We thank K. Shimamoto and D. Miki for providing the plasmids pUbqDsRed, p35S-GFP, and p35S-dsGFP; K. Nakamura for the plasmid pIG121; D. Baulcombe for the plasmid carrying PVY HC-Pro and Agrobacterium C581C1; A. M. Wang for helpful comments on this manuscript; and T. Okuno for the plasmid pBICP35. We also thank D. Murphy and A. A. Arsovski for editing the English in the manuscript.

\section{LITERATURE CITED}

Ainsworth, G. C. 1935. Mosaic disease of cucumber. Ann. Appl. Biol. 22: $55-67$.

Ali, M. E., Waliullah, S., and Nishiguchi, M. 2016. Molecular analysis of an attenuated strain of Cucumber green mottle mosaic virus using in vitro infectious cDNA clone: Pathogenicity and suppression of RNA silencing. J. Plant Biochem. Biotechnol. 25:79-86.

Anandalakshmi, R., Pruss, G. J., Ge, X., Marathe, R., Mallory, A. C., Smith, T. H., and Vance, V. B. 1998. A viral suppressor of gene silencing in plants. Proc. Natl. Acad. Sci. 95:13079-13084.

Baulcombe, D. C. 1999. Gene silencing: RNA makes RNA makes no protein. Curr. Biol. 9:R599-R601.

Bosher, J. M., and Labouesse, M. 2000. RNA interference: Genetic wand and genetic watchdog. Nat. Cell Biol. 2:E31-E36.

Burgyán, J. 2008. Role of silencing suppressor proteins. Pages 69-79 in: Plant Virology Protocols. Methods in Molecular Biology, Vol. 451. G. D. Foster, I. E. Johansen, Y. Hong, and P. D. Nagy, eds. Humana Press, Clifton, NJ.

Catalanotto, C., Azzalin, G., Macino, G., and Cogoni, C. 2000. Gene silencing in worms and fungi. Nature 404:245.

Chen, H., Arsovski, A. A., Yu, K., and Wang, A. 2016. Genome-wide investigation using sRNA-seq, degradome-seq and transcriptome-seq reveals regulatory networks of microRNAs and their target genes in soybean during Soybean mosaic virus infection. PLoS One 11:e0150582.

Chen, H., Samadder, P. P., Tanaka, Y., Ohira, T., Okuizumi, H., Yamaoka, N., Miyao, A., Hirochika, H., Ohira, T., and Tsuchimoto, S. 2008. OsRecQ1, a $Q D E-3$ homologue in rice, is required for RNA silencing induced by particle bombardment for inverted repeat DNA, but not for double-stranded RNA. Plant J. 56:274-286.

Chen, H., Tamai, A., Mori, M., Ugaki, M., Tanaka, Y., Samadder, P. P., Miyao, A., Hirochika, H., Yamaoka, N., and Nishiguchi, M. 2010. Analysis of rice RNA-dependent RNA polymerase 1 (OsRDR1) in virus-mediated RNA silencing after particle bombardment. J. Gen. Plant Pathol. 76:152-160.

Chen, H., Zhang, L., Yu, K., and Wang, A. 2015. Pathogenesis of Soybean mosaic virus in soybean carrying Rsvl gene is associated with miRNA and siRNA pathways, and breakdown of AGO1 homeostasis. Virology 476: 395-404.

Cocozaki, A. I., Ramia, N. F., Shao, Y., Hale, C. R., Terns, R. M., Terns, M. P., and Li, H. 2012. Structure of the Cmr2 subunit of the CRISPR-Cas RNA silencing complex. Structure 20:545-553.

Csorba, T., Bovi, A., Dalmay, T., and Burgyán, J. 2007. The p122 subunit of Tobacco mosaic virus replicase is a potent silencing suppressor and compromises both small interfering RNA- and microRNA-mediated pathways. J. Virol. 81:11768-11780.

Csorba, T., Kontra, L., and Burgyán, J. 2015. Viral silencing suppressors: Tools forged to fine-tune host-pathogen coexistence. Virology 479-480: 85-103.

Ding, X. S., Liu, J., Cheng, N. H., Folimonov, A., Hou, Y. M., Bao, Y., Katagi, C., Carter, S. A., and Nelson, R. S. 2004. The tobacco mosaic virus126-kDa protein associated with virus replication and movement suppresses RNA silencing. Mol. Plant-Microbe Interact. 17:583-592.

Dombrovsky, A., Tran-Nguyen, L. T. T., and Jones, R. A. C. 2017. Cucumber green mottle mosaic virus, rapidly increasing global distribution, etiology, epidemiology, and management. Annu. Rev. Phytopathol. 55:231-256.

Fletcher, J. T., George, A. J., and Green, D. E. 1969. Cucumber green mottle mosaic virus, its effect on yield and its control in the Lea Valley, England. Plant Pathol. 18:16-22.

Goto, K., Kobori, T., Kosaka, Y., Natsuaki, T., and Masuta, C. 2007. Characterization of silencing suppressor $2 \mathrm{~b}$ of cucumber mosaic virus based on examination of its small RNA-binding abilities. Plant Cell Physiol. 48: 1050-1060.

Guo, H. S., and Ding, S. W. 2002. A viral protein inhibits the long range signaling activity of the gene silencing signal. EMBO J. 21:398-407. 
Hagiwara, K., Ichiki, T. U., Ogawa, Y., Omura, T., and Tsuda, S. 2002. A single amino acid substitution in 126-kDa protein of Pepper mild mottle virus associates with symptom attenuation in pepper; the complete nucleotide sequence of an attenuated strain, C-1421. Arch. Virol. 147:833-840.

Hagiwara-Komoda, Y., Hirai, K., Mochizuki, A., Nishiguchi, M., Meshi, T., and Ishikawa, M. 2008. Overexpression of a host factor TOM1 inhibits tomato mosaic virus propagation and suppression of RNA silencing. Virology 376:132-139.

Ichiki, T. U., Nagaoka, E. N., Hagiwara, K., Uchikawa, K., Tsuda, S., and Omura, T. 2005. Integration of mutations responsible for the attenuated phenotype of Pepper mild mottle virus strains result in a symptomless crossprotecting strain. Arch. Virol. 150:2009-2020.

Inoue, T, Inoue, N, Asatani, M., and Mitsuhata, K. 1967. Studies on cucumber green mottle mosaic virus in Japan. Nogaku Kenkyu 51:175-186.

Kasschau, K. D., and Carrington, J. C. 1998. A counterdefensive strategy of plant viruses: Suppression of posttranscriptional gene silencing. Cell 95:461-470.

Knapp, E., Achor, D., and Lewandowski, D. J. 2007. Tobacco mosaic virus defective RNAs expressing C-terminal methyltransferase domain sequences are severely impaired in long-distance movement in Nicotiana benthamiana. Virology 367:82-91.

Knapp, E., Danyluk, G. M., Achor, D., and Lewandowski, D. J. 2005. A bipartite Tobacco mosaic virus-defective RNA (dRNA) system to study the role of the N-terminal methyl transferase domain in cell-to-cell movement of dRNAs. Virology 341:47-58.

Kubota, K., Tsuda, S., Tamai, A., and Meshi, T. 2003. Tomato mosaic virus replication protein suppresses virus-targeted posttranscriptional gene silencing. J. Virol. 77:11016-11026.

Kurihara, Y., Inaba, N., Kutsuna, N., Takeda, A., Tagami, Y., and Watanabe, Y. 2007. Binding of tobamovirus replication protein with small RNA duplexes. J. Gen. Virol. 88:2347-2352.

Liu, D., Shi, L., Han, C., Yu, J., Li, D., and Zhang, Y. 2012. Validation of reference genes for gene expression studies in virus-infected Nicotiana benthamiana using quantitative real-time PCR. PLoS One 7:e46451.

Liu, L., Peng, B., Zhang, Z., Wu, Y., Miras, M., Aranda, M. A., and Gu, Q. 2017. Exploring different mutations at a single amino acid position of Cucumber green mottle mosaic virus replicase to attain stable symptom attenuation. Phytopathology 107:1080-1086.

Matsumoto, K., Johnishi, K., Hamada, H., Sawada, H., Takeuchi, S., Kobayashi, K., Suzuki, K., Kiba, A., and Hikichi, Y. 2009. Single amino acid substitution in the methyltransferase domain of Paprika mild mottle virus replicase proteins confers the ability to overcome the high temperature-dependent $H k$ gene-mediated resistance in Capsicum plants. Virus Res. 140:98-102.

Matzke, M., Matzke, A. J. M., and Kooter, J. M. 2001. RNA: Guiding gene silencing. Science 293:1080-1083.

Miki, D., and Shimamoto, K. 2004. Simple RNAi vectors for stable and transient suppression of gene function in rice. Plant Cell Physiol. 45:490-495.

Motoyoshi, F., and Nishiguchi, M. 1988. Control of virus diseases by attenuated virus strains: Comparison between attenuated strains of cucumber green mottle mosaic virus and tobacco mosaic virus. Gamma Field Symp. Inst. Radiat. Breed. Natl. Inst. Agrobiol. Resour. 27:91-109.

Nishiguchi, M., and Kobayashi, K. 2011. Attenuated plant viruses: Preventing virus diseases and understanding the molecular mechanism. J. Gen. Plant Pathol. 77:221-229.

Oosawa, T. 1990. CGMMV control by its attenuated strain. Pages 48-57 in: Useful Microorganisms in Agriculture. K. Umeya and H. Kato, eds. Youkendou, Tokyo, Japan.

Rajamony, L., More, T. A., Seshadri, V. S., and Varma, A. 1987. Resistance to cucumber green mottle mosaic virus (CGMMV) in muskmelon. Cucurbit Genet. Coop. Rep. 10:58-59.

Reed, J. C., Kasschau, K. D., Prokhnevsky, A. I., Gopinath, K., Pogue, G. P., Carrington, J. C., and Dolja, V. V. 2003. Suppressor of RNA silencing encoded by Beet yellows virus. Virology 306:203-209.
Roy, A., Kucukural, A., and Zhang, Y. 2010. I-TASSER: A unified platform for automated protein structure and function prediction. Nat. Protoc. 5: 725-738.

Shimono, M., Ino, M., Sonoda, S., Fujimura, T., and Nishiguchi, M. 2005. Inverse correlation between mRNA levels in GFP-silenced transgenic $\mathrm{Ni}$ cotiana benthamiana and resistance to Potato virus $X$ engineered to contain GFP sequence. J. Gen. Plant Pathol. 71:147-152.

Silhavy, D., Molnár, A., Lucioli, A., Szittya, G., Hornyik, C., Tavazza, M., and Burgyán, J. 2002. A viral protein suppresses RNA silencing and binds silencing-generated, 21- to 25-nucleotide double-stranded RNAs. EMBO J. 21:3070-3080.

Slavokhotova, A. A., Istomina, E. A., Andreeva, E. N., Korostyleva, T., Pukhalskij, V. A., Shijan, A. N., and Odintsova, T. I. 2016. An attenuated strain of Cucumber green mottle mosaic virus as a biological control agent against pathogenic viral strains. Am. J. Plant Sci. 7:724-732.

Takeda, A., Tsukuda, M., Mizumoto, H., Okamoto, K., Kaido, M., Mise, K., and Okuno, T. 2005. A plant RNA virus suppresses RNA silencing through viral RNA replication. EMBO J. 24:3147-3157.

Tan, S.-H., Nishiguchi, M., Sakamoto, W., Ogura, Y., Murata, M., Ugaki, M., Tomiyama, M., and Motoyoshi, F. 1997. Molecular analysis of the genome of an attenuated strain of cucumber green mottle mosaic virus. Ann. Phytopathol. Soc. Jpn. 63:470-474

Thomas, C. L., Leh, V., Lederer, C., and Maule, A. J. 2003. Turnip crinkle virus coat protein mediates suppression of RNA silencing in Nicotiana benthamiana. Virology 306:33-41.

Torres-Barceló, C., Daròs, J.-A., and Elena, S. F. 2010. HC-Pro hypo- and hypersuppressor mutants: Differences in viral siRNA accumulation in vivo and siRNA binding activity in vitro. Arch. Virol. 155:251-254.

Tsuda, S., Kubota, K., Kanda, A., Ohki, T., and Meshi, T. 2007. Pathogenicity of Pepper mild mottle virus is controlled by the RNA silencing suppression activity of its replication protein, but not the viral accumulation. Phytopathology 97:412-420.

Ugaki, M., Tomiyama, M., Kakutani, T., Hidaka, S., Kiguchi, T., Nagata, R., Sato, T., Motoyoshi, F., and Nishiguchi, M. 1991. The complete nucleotide sequence of cucumber green mottle mosaic virus (SH strain) genomic RNA. J. Gen. Virol. 72:1487-1495.

Valli, A., Dujovny, G., and Garcia, J. A. 2008. Protease activity, self interaction, and small interfering RNA binding of the silencing suppressor p1b from Cucumber vein yellowing ipomovirus. J. Virol. 82:974-986.

Valli, A., Oliveros, J. C., Molnar, A., Baulcombe, D., and Garcia, J. A. 2011. The specific binding to 21-nt double-stranded RNAs is crucial for the antisilencing activity of Cucumber vein yellowing virus $\mathrm{P} 1 \mathrm{~b}$ and perturbs endogenous small RNA populations. RNA 17:1148-1158.

Várallyay, E., and Havelda, Z. 2013. Unrelated viral suppressors of RNA silencing mediate the control of ARGONAUTE1 level. Mol. Plant Pathol. $14: 567-575$.

Vogler, H., Akbergenov, R., Shivaprasad, P. V., Dang, V., Fasler, M., Kwon, M. O., Zhanybekova, S., Hohn, T., and Heinlein, M. 2007. Modification of small RNAs associated with suppression of RNA silencing by tobamovirus replicase protein. J. Virol. 81:10379-10388.

Wang, L. Y., Lin, S. S., Hung, T. H., Li, T. K., Lin, N. C., and Shen, T. L. 2012. Multiple domains of the tobacco mosaic virus p126 protein can independently suppress local and systemic RNA silencing. Mol. PlantMicrobe Interact. 25:648-657.

Waterhouse, P. M., Wang, M.-B., and Lough, T. 2001. Gene silencing as an adaptive defense against viruses. Nature 411:834-842.

Wu, S., and Zhang, Y. 2007. LOMETS: A local meta-threading-server for protein structure prediction. Nucleic Acids Res. 35:3375-3382.

Yoon, J. Y., Ahn, H. I., Kim, M., Tsuda, S., and Ryu, K. H. 2006. Pepper mild mottle virus pathogenicity determinants and cross protection effect of attenuated mutants in pepper. Virus Res. 118:23-30.

Zhang, Y. 2008. I-TASSER server for protein 3D structure prediction. BMC Bioinformatics 9:40. 